Available online at GSC Online Press Directory

GSC Biological and Pharmaceutical Sciences

e-ISSN: 2581-3250, CODEN (USA): GBPSC2

Journal homepage: https://www.gsconlinepress.com/journals/gscbps

(RESEARCH ARTICLE)

\title{
Antibiotic susceptibility profile of Staphylococcus aureus from door handles in Nasarawa State University, Keffi, Nigeria
}

\author{
Owaku Grace ${ }^{1}$, Oti Victor ${ }^{1}$, Tsaku Paul ${ }^{1}$, Ekeleme Kenneth ${ }^{1}$, Anumnu Adaku ${ }^{2}$ and Anzaku Samuel ${ }^{1}$ \\ ${ }^{1}$ Department of Microbiology, Nasarawa State University, PMB 1022, Keffi, Nigeria \\ ${ }^{2}$ Department of Plant Science and Biotechnology, Nasarawa State University, PMB 1022, Keffi, Nigeria
}

Publication history: Received on 12 December 2017; revised on 22 December 2017; accepted on 08 January 2018

https://doi.org/10.30574/gscbps.2018.2.2.0062

\begin{abstract}
This study was carried out in order to determine the prevalence of Staphylococcus aureus on door handles and the antibiotic susceptibility of the organism to some commonly used antibiotics in Nasarawa State University, Keffi, Nigeria. A total of 100 door samples were obtained, 20 each from the five faculties within the university's main campus. These were cultured and identified using appropriate protocols. A total of $26(26.0 \%)$ isolates were identified as Staphylococcus aureus. Faculties of Administration and Arts jointly accounted for the highest prevalence with $40 \%$. The antibiotics susceptibility test revealed that Gentamicin was the most effective of all the test antibiotics against the Staphylococcus aureus isolated. The multidrug resistant $S$. aureus isolates $12(46.2 \%)$ were observed to have produced beta lactamase enzymes implicated in beta lactam antibiotics resistance. Observation from this study showed that there is a high level of antibiotics abuse or misuse with resultant multidrug-resistant $S$. aureus isolates in the study area.
\end{abstract}

Keywords: Staphylococcus aureus; Bacteria; Door Handles; Antibiotics Susceptibility; Minimum inhibitory concentration; Beta lactamase

\section{Introduction}

Infectious diseases transmitted via hand contact have been a global health challenge. Gram positive and negative bacteria most especially are found to contaminate contact surfaces e.g; door handles, tables, chairs, windows etc [1]. Infectious diseases top the list for causes of death worldwide and contribution to morbidity and mortality cannot be readily quantified due to lack of data for most countries and it remains a global concern [2]. Infections and/or diseases gotten by contact with environmental surfaces are common cold and sores, conjunctivitis, giardiasis, diarrhea, impetigo, meningitis, pneumonia etc. These diseases are caused by a myriad of bacterial organisms. [3].

Human hands have been implicated as the major transmitter of microorganisms to environmental surfaces. Curtis and Carncross [4] and Fewtrell et al. [5] reported that hands often act as vectors that carry disease-causing pathogens including bacteria and viruses from person to person either through direct contact or indirectly via surfaces. Defective personal hygiene can facilitate the transmission of some of these pathogenic bacteria found in the environment to human hands [6].

Studies has reported that environmental surfaces which are often touched with hands have higher bacterial load when compared to toilet seats and restroom floor. This outcome might be due to the aggregate contamination of door handles which results from poor sanitary conditions [7]. Hand washing which is traditional was the first line of defense in preventing the spread of disease; it has been neglected and must be embraced vigorously by families, schools and

${ }^{*}$ Corresponding author

E-mail address: obabavictor1@ gmail.com

Copyright (C) 2018 Author(s) retain the copyright of this article. This article is published under the terms of the Creative Commons Attribution Liscense 4.0. 
healthcare professionals. However, many people seem to run water over their hands without using soap and some fail to wash their hands at all after leaving the restroom [8].

Staphylococcus aureus is important pathogens of human and animals that cause both health care associated infections and community acquired infection [9]. It is a pathogen of greater concern because of virulence [10]. Its ability to cause a diverse array of life threatening infections and its ability to adapt to different environment condition [11]. Staphylococcus aureus has been found to be the most frequently isolated pathogen causing blood stream infections, skin and soft tissues infection, bones and joints infection, urinary tract infection and pneumonia [12-15]. Door handles is one of the most implicated probable source of this infections caused by $S$. aureus [16-17].

The infections caused by $S$. aureus can be treated with antibiotics but in recent years $S$. aureus have been reported to be resistant to commonly used antibiotics such as macrolide, lincosamide, streptomycin, tetracycline, gentamicin and betalactam antibiotics [18-20] and the resistant is due to the modification of drug target site, outer membrane modification, production of beta lactamase and efflux pump as a result of misuse, over use and increase of antibiotic to animal feed. Also most of these agent are orally administered which can easily be abuse. In this study, we investigated the antibiotic susceptibility profile of Staphylococcus aureus isolated from door handles in Nasarawa State University Keffi, Nigeria.

\section{Material and methods}

\subsection{Study Area and Population}

The study was conducted in the Microbiology laboratory of Nasarawa State University, Keffi. Keffi is approximately 68 $\mathrm{km}$ from Abuja, the Federal Capital of Nigeria and $128 \mathrm{~km}$ from Lafia, the Capital of Nasarawa State. Keffi township is located between latitude $8^{\circ} 5 \mathrm{~N}$ of the equator and longitude $7^{\circ} 8 \mathrm{E}$ and situated on an altitude of $850 \mathrm{M}$ above sea level [21].

\subsection{Sample Collection}

A total number of 20 samples were obtained from each of the five faculties of the main campus of Nasarawa State University, Keffi (making 100 samples in all). Sterile swab-sticks were used for the collection of specimens. The swabsticks were briefly immersed in normal saline solution prior to swabbing of the door handle, and the specimen was taken to laboratory immediately for analysis. The swab-sticks containing the specimen were inoculated on nutrient broth and incubated at $37^{\circ} \mathrm{C}$ for 18 hours. These was then sub-cultured on Mannitol Salt Agar by streaking, and incubated at $37^{\circ} \mathrm{C}$ for 24 hours, golden-yellow colonies were observed, Gram's stain, catalase and coagulase tests were used to identify $S$. aureus isolates.

\subsection{Antibiotics Susceptibility Test}

The antibiotics were tested against the isolates using the Kirby-Bauer disc diffusion method on Mueller Hinton Agar. Bacterial culture suspended in saline equivalent to 0.5 MacFarland was spread on Mueller Hinton Agar and allowed to dry at room temperature. Each antibiotic disc was placed at $20 \mathrm{~mm}$ distance from each other on the inoculated agar and incubated at $37^{\circ} \mathrm{C}$ for 24 hours. The inhibition zones were measured using graduated meter rule to determine the diameter of the inhibition zones and interpreted as sensitive and resistant, according to CLSI guidelines [22].

\subsection{Determination of Minimum Inhibitory Concentrations}

The minimum inhibitory concentration (MIC) of the antibiotics used was studied using standard agar dilution method following the procedures described in the Clinical Laboratory Standard Institute Manual [22]. The isolates obtained were standardized to 1 in 5000 dilution using a micro pipette to transfer the organism into a solution of normal saline.

Double strength Mueller Hinton agar was prepared and 10mls was dispensed into each bottle and sterilized. Each agar bottle was diluted with antibiotics divided into 9 different concentrations; four concentrations below and four concentrations above the breakpoint value of European Committee on Antimicrobial Susceptibility Testing [23]. Antibiotics were not added to some agar bottles; this was to serve as control signifying viability of the organisms used. Antibiotic-agar mixtures were poured into sterilized petri dishes and allowed to solidify. The petri dishes were labeled accordingly and the standardized organisms were inoculated, this was allowed to stand for 1hour for proper diffusion of organism after which it was incubated for 24 hours. The lowest concentration that inhibited growth was the MIC. 


\subsection{Detection of $\beta$-lactamase Enzymes Producing Staphylococcus aureus}

Iodometric and acidometric methods were used in the detection of $\beta$-lactamase producing species of Staphylococcus aureus from selected multiple antibiotics resistant isolates using standard procedures as described by Samant and Pai, $[24]$.

\subsubsection{Iodometric Method}

$100 \mu \mathrm{l}$ of penicillin solution was dispensed into a well of microtitre plate. Several colonies of the organism to be tested were emulsified into the solution to get dense suspension. Two drops of starch were added and then the plate was kept at room temperature for 30-60 minutes. One drop of iodine was then added which turn the solution blue. If the blue colour disappeared in 10 minutes, the organism was considered as $\beta$ lactamase positive. Negative control with penicillin alone was kept without any culture suspension. B-lactamase producing strain of S. aureus ATCC 29213 was used as positive control [25].

\subsubsection{Acidometric Method}

$100 \mu \mathrm{l}$ of penicillin phenol red solution was placed in the well of microtitre plate. Several colonies were suspended in the solution to get dense suspension. The solution turned yellow within 10-15 minutes if $\beta$ Lactamase enzyme was produced. Colour changes after 15 minutes is not of significance since it represents decomposition of substrate [26-28].

\section{Results and discussion}

Of the 100 door handles examined, 26 (26\%) S. aureus was isolated and identified. The isolation frequency based on different locations in the study area showed that Faculty of Law 1 (5\%) has the least prevalence while the faculties of Administration and Arts both with 8 (40\%), have the highest prevalence of the bacterial isolates. Other locations includes Faculty of Natural and Applied Sciences and Faculty of Social Sciences with prevalence of 4 (20\%) and 5 (25\%) respectively (Table 1).

Table 1 Isolation of Staphylococcus aureus from door handles in Nasarawa State University, Keffi, Nigeria

\begin{tabular}{llll}
\hline S/No. & Faculty & No. of Samples & No. of Isolates (S. aureus) (\%) \\
\hline 1 & Administration & 20 & $8(40 \%)$ \\
2 & Art & 20 & $8(40 \%)$ \\
3 & Law & 20 & $1(5 \%)$ \\
4 & Natural \& Applied Sciences & 20 & $4(20 \%)$ \\
5 & Social Sciences & 20 & $5(25 \%)$ \\
\hline
\end{tabular}

Table 2 Profile of Antibiotic-resistant Staphylococcus aureus isolates from door handles in Nasarawa state University, Keffi, Nigeria

\begin{tabular}{lccccc}
\hline Antibiotics & \multicolumn{3}{c}{ Antibiotic Resistance S. aureus (\%) } \\
\cline { 2 - 6 } & $\begin{array}{c}\text { Administration } \\
(\mathbf{n = 8 )}\end{array}$ & $\begin{array}{c}\text { Art } \\
(\mathbf{n = 8})\end{array}$ & $\begin{array}{c}\text { Law } \\
(\mathbf{n = 1})\end{array}$ & $\begin{array}{c}\text { NAS } \\
(\mathbf{n}=\mathbf{4})\end{array}$ & $\begin{array}{c}\text { Social Sciences } \\
(\mathbf{n}=\mathbf{5})\end{array}$ \\
\hline Gentamycin & 50 & 62.5 & - & 25 & 40 \\
Cotrimoxazole & 87.5 & 87.5 & 100 & 100 & 60 \\
Erythromycin & 100 & 100 & - & 100 & 80 \\
Ciprofloxacin & 100 & 100 & 100 & 100 & 100 \\
Ofloxacin & 80 & 87.5 & - & 25 & 60 \\
Augmentin & 100 & 100 & 100 & 75 & 80 \\
Ceftazidime & 87.5 & 100 & 100 & 100 & 100 \\
Cefuroxime & 100 & 100 & 100 & 100 & 100 \\
Multiple Antibiotics Resistance & 7 & 8 & 4 & 6 & 7 \\
\hline
\end{tabular}

The antibiotics susceptibility study showed the multiple antibiotics resistance spread in the order; Faculty of Arts (8) > Faculty of Administration (7) = Faculty of Social Sciences (7) > Faculty of Natural and Applied Sciences (6) > Faculty of Law (4). Cefuroxime and ciprofloxacin were $100 \%$ ineffective in all the Faculties (Table 2). 
All the isolates were found to be resistant to multiple antibiotics and the MAR Index ranges are shown in table 3 below. While the MICs of the test antibiotics are shown in table 4.

Table 3 Multiple Antibiotics Resistance Index (MARI) Ranges in Faculties of Nasarawa State University, Keffi, Nigeria

\begin{tabular}{ll}
\hline Faculties & MARI Ranges \\
\hline ADM $(\mathrm{n}=8)$ & $0.63-1.00$ \\
ART $(\mathrm{n}=8)$ & $0.63-1.00$ \\
LAW $(\mathrm{n}=1)$ & $0.63-1.00$ \\
NAS $(\mathrm{n}=4)$ & $0.63-1.00$ \\
SOC $(\mathrm{n}=5)$ & $0.65-1.00$ \\
\hline
\end{tabular}

Key: $\mathrm{ADM}=$ Administration; $\mathrm{ART}=$ Art $; \mathrm{LAW}=$ Law NAS $=$ Natural and Applied Sciences $; \mathrm{SOC}=$ Social Sciences

Table 4 Minimum Inhibitory Concentration of test antibiotics against Staphylococcus aureus isolates in Nasarawa State University, Keffi, Nigeria

\begin{tabular}{llll}
\hline Test Antibiotics & PPL $(\boldsymbol{\mu g} / \mathbf{m l})$ & MIC Range $(\boldsymbol{\mu g} / \mathbf{m l})$ & No. of Resistant Isolates (\%) \\
\hline AUG & 5.00 & $2.50-80.00$ & $23(88.46)$ \\
GEN & 10.0 & $0.63-160.0$ & $11(42.31)$ \\
CRX & 2.20 & $3.25->35.2$ & $26(100.00)$ \\
CXC & 1.00 & $4.00-16.00$ & $26(100.00)$ \\
OFL & 4.70 & $0.06-16.00$ & $8(30.80)$ \\
\hline \multicolumn{2}{r}{ Key: AUG = augmentin; CRX = ciprofloxacin; OFL = ofloxacin; GEN = gentamicin; CXC = cefuroxime; PPL = peak plasma level }
\end{tabular}

All the test isolates which were resistant to the penicillin antibiotics were confirmed to be beta lactamase producers and the result is shown in table 5 below.

Table 5 Beta lactamase enzymes production test on selected multi-antibiotics resistant Staphylococcus aureus isolates from door handles in Nasarawa state university, Keffi

\begin{tabular}{llcc}
\hline S/No. & Isolates & Acidometric & Iodometric \\
\hline 1 & ADM01 & + & + \\
2 & ADM02 & + & + \\
3 & ADM05 & + & + \\
4 & ADM14 & + & + \\
5 & ART01 & + & + \\
6 & ART02 & + & + \\
7 & ART03 & + & + \\
8 & ART09 & + & + \\
9 & ART14 & + & + \\
10 & ART17 & + & + \\
11 & NAS01 & + & + \\
12 & SOC03 & + & + \\
\hline
\end{tabular}

This study was designed to isolate $S$. aureus from door handles in Nasarawa State University, Keffi, Nigeria and to study its susceptibility to commonly prescribed antibiotics. A total of 26 isolates were obtained and identified as $S$. aureus out of 100 door samples obtained. This prevalence rate is relatively high as compared to the one reported by Stanley et al. [29] in Port Harcourt, Nigeria which found the incidence of $S$. aureus to be $6.9 \%$, and $7.7 \%$ among pregnant and non- 
pregnant women respectively. However, Kajela and Bacha [30] reported a higher prevalence of 39\% in a study conducted in Ethiopia. In another study, Adamu et al. [31] reported a prevalence of 52\% among apparently healthy humans in Maiduguri, Nigeria. The isolation differences among the five different faculties in Nasarawa state university, Keffi showed both faculty of Administration 8(40\%) and faculty of Arts 8(40\%) with the highest frequency of isolation of $S$. aureus, while the faculty of Law $1(5 \%)$ has the least frequency of isolation. The faculty of Social Sciences and faculty of Natural and Applied Sciences has 5(25\%) and 4(20\%) respectively. This may be due to the hygienic standards and the population distribution across the different faculties.

The antibiotics susceptibility study showed the multiple antibiotics resistance spread in the order; Faculty of Arts (8) > Faculty of Administration (7) = Faculty of Social Sciences (7) > Faculty of Natural and Applied Sciences (6) > Faculty of Law (4). Cefuroxime and Ciprofloxacin were $100 \%$ ineffective in all the Faculties. The S. aureus isolates susceptibility study showed that augmentin was ineffective against all test organisms from all faculties except in faculties of Social sciences and Natural and applied sciences with $20 \%$ and $25 \%$ respectively.

Generally, cotrimoxazole, erythromycin, ciprofloxacin, cefuroxime, ceftazidime and ofloxacin were not effective against the test $S$. aureus isolates in this study. The exception in this observation was gentamicin, a parenteral product, which showed high level of activity. The order of gentamicin effective activity against test bacterial isolates from different faculties was faculty of Law (100\%) greater than Natural and applied science (75\%) greater than Social science (60\%) greater than Administration (50\%) greater than Arts (37.50\%). It was observed that all effective antibiotics against test bacterial isolates were sold in dosage forms which can be self-dispensed, contrary to gentamicin which is an injectable drug. The antibiotic susceptibility study on isolated $S$. aureus showed a remarkably high percentage of resistance to the test antibiotics. This however is not in contrast with most studies conducted by other researchers with emphasis of resistance to penicillins [29-31].

Twelve (46.2\%) of the isolates were found to be multi-antibiotic resistant, and were also $100 \%$ resistant to augmentin and cephalosporins. These multi antibiotics resistant test $S$. aureus isolates were observed to have produced beta lactamase enzymes [32]. Therefore, this observation laid credence to the observed resistance of test organisms to augmentin and cephalosporins.

This study shows a high level of multidrug-resistant $S$. aureus and a looming epidemic of Staphylococcal infections through door handles. There is therefore, the need for an improvement in personal hygiene by the staff and students of Nasarawa State University, Keffi.

This study has shown that most of the antibiotics studied were ineffective against the test $S$. aureus isolates. However, gentamicin was shown to be moderately effective in arresting the growth of $S$. aureus isolates. Care is needed to arrest the emerging multidrug-resistant $S$. aureus in this locality. Abuse of these drugs should be avoided. The rate of antibiotics ineffectiveness observed in this study, suggests the need for an alternative remedy against $S$. aureus. Indiscriminate use of antibiotics and self-medications should be discouraged.

\section{Conclusion}

In conclusion, this study has revealed the poor standard of hygiene, especially, hand washing among the people in Nasarawa State University, Keffi. This should be considered as a timely warning and proactive measures should be taken to prevent an outbreak of epidemics that could become difficult to handle. It should be considered that $S$. aureus is just one out of millions of other microorganisms that may colonise the same surface at the same time. These therefore implies that it is possible to be infected with different other microorganisms with greater virulence. Also, the level of multidrug-resistant $S$. aureus isolates is high and should therefore be taken into consideration. Gentamicin is moderately effective against the test $S$. aureus isolates, this could be due to the fact that the drug is usually administered through parenteral routes and not easily abused; therefore care should be taken in order to avoid the abuse of these drug which could lead to resistance.

\section{Compliance with ethical standards}

\section{Acknowledgments}

The researchers acknowledge the contributions of the staffs of Microbiology Department, Nasarawa State University, Keffi, Nigeria for their contribution in this study. 


\section{Disclosure of conflict of interest}

Authors have declared that no competing interests exist.

\section{References}

[1] Itah AY and Ben AE. (2004). Incidence of enteric bacteria and Staphylococcus aureus in Daycare Centers in Akwa Ibom State, Nigeria. The Southeast Asian Journal of Tropical Medicine and Public Health, 35(1), 9-202.

[2] Barbosa TM and Levy SB. (2000). The impact of antibiotic use on resistance development and persistence. Drug Resistance Updates, 3, 303-311.

[3] World Health Organization. (1980). Escherichia coli diarrhea. Bull. World Health Organization, 58(1), 23-36.

[4] Curtis V and Carncross S. (2003). Effect of washing hands with soap on diarrhoea risk in the community: A systemic review. The Lancet Infectious Diseases, 3, 275-281.

[5] Fewtrell L, Pruss-Ustun A, Bos R and Gore FB. (2007). Water, sanitation and hygiene: quantifying the health impact at national and local levels in countries with incomplete water supply and sanitation coverage. (WHO Environmental Burden of Disease Series No. 15). World Health Organization, Geneva.

[6] Mensah P, Mann DY, Danko KO and Ablodey A. (2002). Street foods in Ghana. How safe are they? Bull. World Health Organ, 80(7), 546-584.

[7] Augustino C, Asha L, Joel M, Alexanda M, Eliakunda M, Elisa M, Isaac M and Emma P. (2014). Determination of bacterial load and antibiotic susceptibility testing of bacteria isolated from students' toilets at Sokoine University of Agriculture, Morogoro, Tanzania. Journal of Health, Medicine and Nursing, 5.

[8] Barker J and Bloomfield SF. (2000). Survival of salmonella in bathrooms and toilets in domestic homes following salmonellosis. Journal of Applied Microbiology, 89(1), 137-144.

[9] Shen H, Akoda E and Zhang K. (2013). Methicillin-resistant Staphylococcus aureus carriage among students at a historically black university: a case study. International Journal of Microbiology, Article ID 979734, 7 pages.

[10] Chamber HF. (2005). Community-associated MRSA-resistance and virulence converge. The New England Journal of Medicine, 3(52), 7-1485.

[11] Lowy FD. (2003). Antimicrobial Resistance: the example of Staphylococcus aureus. Journal of Clinical Investigation, 111(9), 1265-1273.

[12] Doern GV, Brueggemann AB, Pfaller MA and Jones RN. (1999). Assessment of laboratory performance with Streptococcus pneumoniae antimicrobial susceptibility testing in the United States: A report from the college of American pathologists microbiology proficiency survey program. Archives of Pathology Laboratory and Medicine, 123, 9-285.

[13] Sader H, Sampaio JL, Zoccoli C and Jones RN. (1999). Results of the 1997 SENTRY antimicrobial surveillance Program in three Brazilian Medical Centers. Brazilian Journal of Infectious Diseases, 3, 63-79.

[14] Jones RC, Deck J, and Hart EM. (2008). Relative quantitative comparisons of the extracellular protein profiles of Staphylococcus aureus UAMS-1 and its sarA, agr, and sarA agar regulatory mutants using on-dimensional polyacrylamide gel electrophoresis and nanocapillary liquid chromatography coupled with tandem mass spectrometry. Journal of Bacteriology, 190(15), 78-5265.

[15] Klein EY, Sun L, Smith DL and Laxminarayan R. (2013). The changing epidemiology of methicillin-resistant Staphylococcus aureus in the United States: a national observational study. The American Journal of Epidemiology, 177(7), 74-666.

[16] Reynolds KA. (2005). Hygiene of Environmental Surfaces. International Journal of Environmental Health Science Research, 15(3), 34-225.

[17] Nworie A, Ayeni JA, Eze UA and Azi SO. (2012). Bacterial contamination of door handles/knobs in selected public conveniences in Abuja metropolis, Nigeria: a public health threat. Continental Journal of Medical Research, 6(1), 7-11.

[18] Gould MI. (2005). The clinical significance of methicillin-resistant Staphylococcus aureus. Journal of Hospital Infection, 61(4), 82-277. 
[19] Delorme T, Rose S, Senita J, Callahan C and Nasr P. (2009). Epidemiology and susceptibilities of methicillinresistant Staphylococcus aureus in North-eastern Ohio. The American Journal of Clinical Pathology, 132 (5), 616687.

[20] David MZ and Daum RM. (2010). Community-associated methicillin-resistant Staphylococcus aureus. Journal of Clinical Microbiology Review, 23(3), 87-616.

[21] Akwa VL, Binbol NL, Samaila KL and Marcus ND. (2007). Geographical perspective of Nasarawa State. Keffi: Onaivi Printing and Publishing Company.

[22] Clinical and Laboratory Standards Institute. (2012). Performance standards for antimicrobial susceptibility testing. 22nd Informational Supplement M100-S22. Wayne, PA, USA.

[23] EUCAST. (2015). The european committee on antimicrobial susceptibility testing. Breakpoint tables for interpretation of MICs and zone diameters. Version 5.0. http://www.eucast.org

[24] Samant SA and Pai CG. (2012). Comparative evaluation of $\beta$ lactamase detection methods in Staphylococci. International Journal of Research in Pharmaceutical and Biomedical Sciences, 3(4), 8-1580.

[25] Catlin BW. (1975). Iodometric detection of Haemophilus beta lactamase; rapid presumptive test for ampicillin resistance. Journal of Antimicrobial Agents and Chemotherapy, 7, 265-270.

[26] Boxer GE and Everett PM. (1949). Colorimetric determination of benzyl penicillin. Annals of Chemistry, 2(1), 670673.

[27] Rubin FA and Smith DH. (1973). Characterization of R-factor Beta lactamases by the acidometric method. Journal of Antimicrobial Agents and Chemotherapy, 3: 68-73.

[28] Thornsberry C and Kirven LA. (1974). Ampicillin resistance in Haemophilus influenzae as determined by a rapid test for Beta lactamase production. Journal of Antimicrobial Agents and Chemotherapy, 6: 653-654.

[29] Stanley CN, Ugboma HAA, Ibezim EC and Attama AA. (2013). Prevalence and antibiotic susceptibility of Staphylococcus aureus and other Staphylococcal Infections in pregnant women attending antenatal clinic in a tertiary hospital in Port Harcourt, Nigeria. Journal of Infectious Diseases and Therapy, 1,125

[30] Kejela T and Bacha K. (2013). Prevalence and antibiotic susceptibility pattern of methicillin-resistant Staphylococcus aureus (MRSA) among Primary school children and prisoners in Jimma town, Southwest Ethiopia. Annals of Clinical Microbiology and Antimicrobials, 12(11), 1-11.

[31] Adamu YJ, Raufu AI, Chimaroke FC and Ameh A. (2010). Antimicrobial susceptibility testing of Staphylococcus aureus isolated from apparently healthy humans and animals in Maiduguri, Nigeria. International Journal of Biomedical and Health Sciences, 6 (4), 5-191.

[32] Isenberg DH. (2004). Clinical microbiology procedures handbook (2 ${ }^{\text {nd }}$ Ed). ASM Press; ISBN 1555812902/155581-2-290.

\section{How to cite this article}

Owaku G, Oti V, Tsaku P, Ekeleme K, Anumnu A and Anzaku S. (2018). Antibiotic susceptibility profile of Staphylococcus aureus from door handles in Nasarawa State University, Keffi, Nigeria. GSC Biological and Pharmaceutical Sciences, 2(2), 33-39. 